ISSN 2236-0859

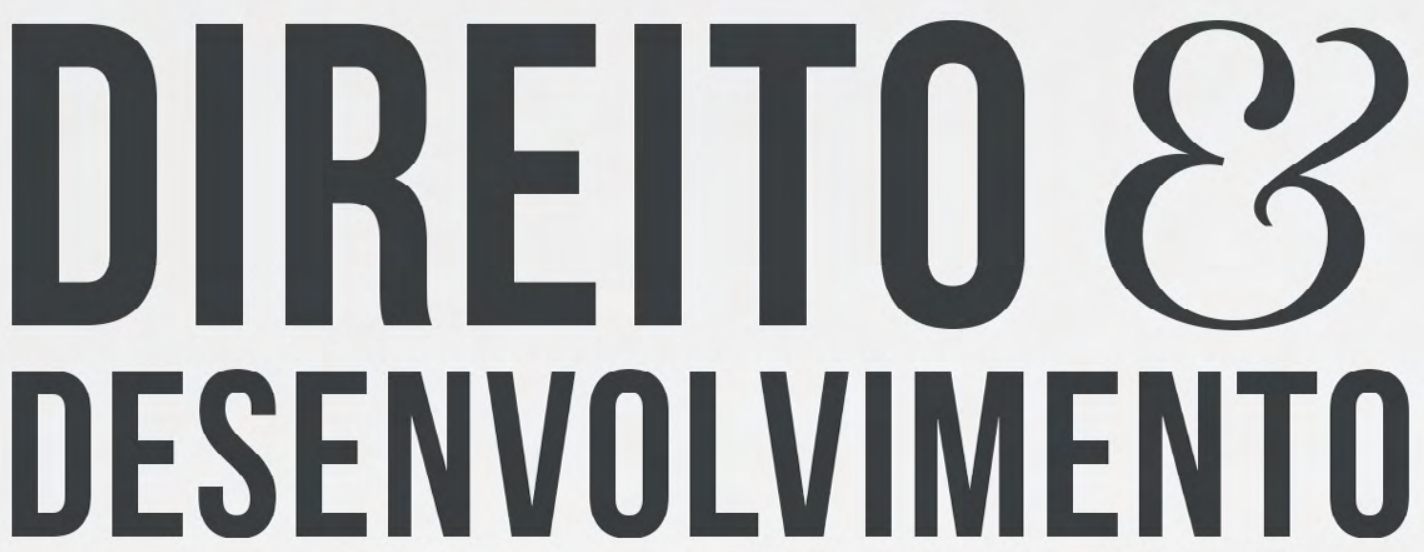

REVISTA DO PROGRAMA DE PÓS-GRADUAÇÃO EM DIREITO MESTRADO EM DIREITO E DESENVOLVIMENTO SUSTENTÁVEL

\title{
UMA PROPOSTA DE DISCUSSÃO DA RELAÇÃO ENTRE DESENVOLVIMENTO HUMANO E A EFICÁCIA HORIZONTAL DOS DIREITOS FUNDAMENTAIS PREPONDERANTES EM ALGUNS PAISES DEMOCRÁTICOS OCIDENTAIS
}

ELOY PEREIRA LEMOS JÚNIOR

LEONARDO ALEXANDRE TADEU CONSTANT DE OLIVEIRA 


\title{
UMA PROPOSTA DE DISCUSSÃO DA RELAÇÃO ENTRE DESENVOLVIMENTO HUMANO E A EFICÁCIA HORIZONTAL DOS DIREITOS FUNDAMENTAIS PREPONDERANTES EM ALGUNS PAÍSES DEMOCRÁTICOS OCIDENTAIS
}

\author{
A PROPOSAL FOR DISCUSSION OF THE RELATIONSHIP BETWEEN HUMAN \\ DEVELOPMENT AND THE HORIZONTAL EFFECTIVENESS OF PREPONDERANT \\ FUNDAMENTAL RIGHTS IN SOME WESTERN DEMOCRATIC COUNTRIES
}

Recebido: $14 / 12 / 2017$

Aprovado: 20/04/2018
Eloy Pereira Lemos Júnior* Leonardo Alexandre Tadeu Constant de Oliveira**

\begin{abstract}
RESUMO: O artigo propõe-se a discutir os impactos no desenvolvimento humano pela adoção de normas de direitos humanos como normas fundamentais, especificamente quanto a sua eficácia horizontal nas relações privadas. Parta tanto formou-se um supedâneo com as principais teorias sobre o efeito horizontal das normas de direito fundamental adotadas nos países democráticos ocidentaise, a partir de uma tendência doutrinária adotada pelas cortes constitucionais destes países, buscou-se projetar as implicações sobre o desenvolvimento pela maior ou menor limitação da autonomia privada, considerando precipuamente a eficácia horizontal das normas de direitos fundamentais. Propõe-se ainda a discussão se haveria relação entre o desenvolvimento e a efetividade dos direitos fundamentais pelo Estado através dos particulares ou uma transferência do ônus aos mesmos, especialmente nas relações privadas, a partir justamente das violações ocorridas nas relações privadas. $\mathrm{O}$ artigo valeu-se da pesquisa teórico-bibliográfica, sendo a medida do desenvolvimento feita com base nos indicativos do Îndice de Desenvolvimento Humano (IDH) pelo PNUD/ONU, utilizado o método comparativo. As tendências a adoção de teorias para direitos fundamentais pelas cortes dos respectivos países foram obtidas através da pesquisa teórico-bibliográfica, numa perspectiva histórica sobre a autonomia privada e sobre o permissivo a sua limitação pelos direitos fundamentais nas relações privadas.
\end{abstract}

Palavras-chave: Direitos Fundamentais. Desenvolvimento Humano. IDH. Autonomia Privada. Eficácia Horizontal.

\begin{abstract}
The article proposes to discuss the impacts on human development by adopting human rights norms as fundamental norms, specifically regarding their horizontal effectiveness in private relations. So much has formed a suppository with the main theories on the horizontal effect of the norms of fundamental right adopted in the western democratic countries and, from a doctrinal tendency adopted by the constitutional courts of these countries, it was tried to project the implications on the development by the more or less restriction of private autonomy, taking into account the horizontal effectiveness of the fundamental rights norms. It is also proposed to discuss whether there is a relationship between the development and effectiveness of the fundamental rights by the State through individuals or a transfer of the burden to them, especially in private relations, based precisely on the violations that occurred in private relations. The article was based on the theoretical-bibliographic research, and the development measure

* Doutor em Direito Empresarial pela UFMG (2007), mestrado e especializações. Foi bolsista CAPES em 2005 na Universidade de Lisboa e da FUNDEP-UFMG em 2013. Pós-doutorando como professor visitante em estágio pós-doutoral sênior em Direito na PUCMG e em Administração na FUMEC. Avaliador de cursos de direito pelo INEP-MEC (desde 2010). Professor titular do mestrado e da graduação da Universidade de Itaúna (MG) e FUPAC - Nova Lima (MG). E-mail: eloy.junior@uol.com.br

** Mestre em Direitos Fundamentais pela Universidade de Itaúna - MG (2008), especialista em Direito Tributário pela Universidade Gama Filho-RJ (2007). Professor de Direito Administrativo (SENAC-MG, 2008-20o9) e Direito Civil (Universidade de Itaúna/MG, 2016-2017). Advogado Tributarista e Consultor Empresarial. E-mail: leonardoconstant@hotmail.com
\end{abstract}


was based on the Human Development Index (HDI) by the UNDP/UN, using the comparative method. The tendencies to adopt theories for fundamental rights by the courts of the respective countries were obtained through the theoretical-bibliographical research, in a historical perspective on the private autonomy and on the permissive its limitation by the fundamental rights in the private relations.

Keywords: Fundamental Rights. Human Development. HDI. Private Autonomy. Horizontal Effectiveness.

\section{INTRODUÇÃO}

A adoção dos direitos humanos nas Constituições preponderantemente ocidentais são um movimento recente e de amplo estudo por parte dos Juristas, especialmente se comparado as disposições legais de ordem civil, que são objeto de estudo desde os Romanos. Desta forma, se os direitos humanos foram revigorados e redeclarados após os horrores das guerras da primeira metade do século XX, passando a integrar as Constituições, notadamente a partir da Constituição Mexicana e Alemã, na condição de normas fundamentais, o alcance desta fundamentalidade tem sido objeto das mais sérias e profundas discussões doutrinárias contemporâneas.

Este panorama é multifacetado nos diversos países, especialmente ante as condições sociais, culturais e econômicas, em outra vertente bastante controversa que é o direito ao desenvolvimento. As discussões em torno de um direito ao desenvolvimento remontam a 1945 e o pós-guerra, e naquele momento desenhava-se o modelo ocidental de desenvolvimento, consagrado pelas Nações Unidas e que pregava o desenvolvimento a partir do crescimento econômico, felizmente modificado para o desenvolvimento tecnológico, social e ambiental.

Desde então a busca pelo estado de desenvolvimento pleno é o motivo de todas as sociedades, e é como classifica-se a condição de cada Estado, sendo que cada Estado busca, ou deveria buscar, o oferecimento das mais diversas condições e prestações favoráveis aos seus cidadãos. No intuito de mensurar o desenvolvimento, os Estados são comumente classificados em indicadores. Estas classificações vão desde a riqueza per capta (Produto Interno Bruto - PIB) até o índice de desenvolvimento humano (IDH), e apesar de serem índices estatísticos frios, são efetivamente os índices que governam as decisões dos governos no sistema capitalista, que é o sistema econômico vigente e no qual tanto o Sistema de Justiça quanto o Sistema Normativo estão inseridos, bem como as Constituições e suas normas fundamentais.

$\mathrm{Na}$ seara do desenvolvimento, entre a riqueza e a pobreza e o desenvolvimento e o subdesenvolvimento, os diversos países refletem necessariamente as possibilidades de cada um em oferecer um sistema de justiça consonante com o sistema normativo, de modo que o nível de democracia enquanto corolário dos valores sociais transmudados do mundo axiológico para o mundo deontológico na forma das legislações e especialmente da Constituição, pode ser medido por sua efetividade enquanto prestação jurisdicional relacionada a prestação social.

O contraponto entre direitos fundamentais efetivos e programáticos tem sido decisivo em muitas das interpretações sobre direitos fundamentais, sendo que tem cabido às Cortes Constitucionais a decisão sobre esta eficácia, numa correlação entre direito e possibilidade.

Se há discussão na eficácia vertical das normas de direitos fundamentais, notadamente direitos materiais coletivos, muito atinente a necessidade e possibilidade estatal e sua extensão, as discussões sobre eficácia horizontal das normas de direitos fundamentais centram desde a oponibilidade até a extensão, e carregam um contexto vasto de história, valores, economia e política, numa intrigante discussão.

Neste contexto, este artigo pretende, na medida em que os modelos Constitucionais adotam regras universais de Direitos Humanos como normas fundamentais, fomentar e pontuar a discussão sobre 
se haveria relação entre o desenvolvimento e a efetividade dos direitos fundamentais nas relações privadas, uma vez que na seara do direito privado acontecem violações aos Direitos Fundamentais. A discussão entre dois detentores de direitos fundamentais ou mesmo entre particulares remete a esta questão chave sobre o Sistema Jurídico: o efeito horizontal dos Direitos Fundamentais.

Efetivamente, a oponibilidade e a exigibilidade dos direitos fundamentais em relação aos Estados tem sido a acepção clássica, mas os Direitos Fundamentais, ante sua fundamentalidade, passam a constituir valores que irradiam efeitos por todo o sistema jurídico, e é justamente neste ponto que emerge a dúvida sobre sua aplicação nas relações que envolvem dois sujeitos detentores de direito fundamental, ou seja, na sua eficácia horizontal. Até onde a atuação dos Estados enquanto Juízes podem/devem aprofundar nas relações privadas sem que se comprometa a autonomia privada é uma grande dúvida.

A despeito de haver consagradas teorias a respeito da eficácia horizontal, a sua associação ao desenvolvimento dos países merece destaque, especialmente ante a condição dos Estados em prover ou não a segurança jurídica dos seus julgados e do seu sistema legal, de forma a prover também direitos aos seus cidadãos na seara privada. Nunca é demais lembrar que o ordenamento jurídico é a expressão da democracia enquanto ação legislativa popular e a democracia é uma baliza de desenvolvimento, bem como a segurança jurídica, sendo dois itens de suma importância para todas as relações sociais num Estado e entre os Estados, sendo o supedâneo para a própria força motriz da sociedade que é a autonomia privada.

A discussão sobre desenvolvimento remete a diversos pontos, abrindo o direito mundial a uma dúvida se o fortalecimento das normas fundamentais das Constituições implicaria em cerceamento da autonomia privada ou se as normas de direitos fundamentais implicariam em garantia efetiva deste direito, eis que, sob a perspectiva do desenvolvimento, a autonomia privada tem sido um grande diferencial no desenvolvimento, especialmente se tratando de uma sociedade marcada pelo sistema de economia de mercado.

\section{DESENVOLVIMENTO}

A pesquisa vale-se do método indutivo-dedutivo, partindo do estudo das normas e dos efeitos das normas de direitos fundamentais (vertical e horizontal) bem como das teorias que explicam a eficácia horizontal dos direitos fundamentais e sua adoção por cada um dos países usados como referência na pesquisa. A partir das teorias adotados, definidas pelos entendimentos das cortes constitucionais de cada país, fez-se uma associação ao seu índice de desenvolvimento humano (IDH), no sentido de verificar a ocorrência de alguma associação possível entre o dado desenvolvimento e a proteção aos direitos fundamentais e/ou autonomia privada.

Com fim de elucidar resultados obtidos e oferecer subsídios para mais pesquisas, foram apresentadas considerações, obviamente limitadas ao escopo da pesquisa, que englobou apenas os países ocidentais mais citados pela Doutrina comparada, tanto no sistema "civil law" quanto no sistema "common law".

O desenvolvimento do artigo foi dividido em tópicos, o primeiro intitulado "A origem da fundamentalidade das normas de direito fundamental", tratou de formar um supedâneo sobre o que torna uma norma fundamental, e antecipando a sua força valorativa enquanto originária de uma transformação valorativa para o mundo deontológico.

No segundo intitulado "Eficácia horizontal das Normas de Direito Fundamental", procurase abordar as características das normas de direito fundamentais e seus efeitos perante terceiros sob a perspectiva das principais teorias classicamente consagradas. Nesta sessão, procurou-se abarcar todo o range de atuação das normas nas relações entre particulares, desde a ineficácia até a eficácia direta.

O terceiro tópico intitulado "As teorias sobre a eficácia horizontal dos direitos fundamentais", faz uma análise sobre as principais teorias que estudam a eficácia horizontal e foram consagradas na doutrina. O quarto tópico intitulado "O desenvolvimento e a eficácia horizontal dos direitos fundamentais" procura 
aliar o acolhimento pelos Tribunais Superiores de alguns países ocidentais conforme doutrina e de acordo com o IDH/PNUD da ONU, a aplicação de alguma das teorias de forma preponderante nos julgados destes Tribunais, de forma a estabelecer alguma relação entre seu desenvolvimento e a teoria adotada, associando a fatores históricos e peculiares de cada Estado.

Nas considerações finais foram apresentadas algumas observações que remetem a pesquisa, bem como foram explicitados campos para futuras pesquisas no mesmo sentido, de forma a convalidar sua importância e aprofundar os temas.

\section{A ORIGEM DA FUNDAMENTALIDADE DAS NORMAS DE DIREITO FUNDAMENTAL}

Uma norma é de direito fundamental quando é incorporada na Constituição um imperativo de direito do campo axiológico passando ao campo deontológico. Implica valor enquanto parte de um consenso de uma sociedade e na sua inclusão na base Constitucional, pois uma norma fundamental, antes de ser constitucional, deve trazer o que uma comunidade de um Estado entende ser Direito Humano.

Conforme Alexy (2008) a fundamentalidade de uma norma pode ser dividida em formal e substancial, sendo a fundamentalidade formal à simples posição no ápice da estrutura escalonada no ordenamento jurídico como direitos que vinculam diretamente os poderes do Estado e a fundamentalidade substancial implica se tratarem de valores transmudados em de direitos pelos quais são tomadas decisões sobre a estrutura normativa básica do Estado e da sociedade.

Tem-se a partir das fundamentalidades formal e material que os direitos fundamentais das normas de direito fundamental desempenham um papel central no sistema jurídico, já que implicam na inserção de valores no sistema jurídico, valores democraticamente erigidos a normas, de forma que a Constituição, enquanto ápice do sistema normativo formal.

Para destacara importância da norma fundamental ea complementariedade queéa sua condiçãode legal Constitucional e valorativa, o mesmo Alexy (2008), propõe dois modelos hipotéticos de Constituição, baseado nas duas normas: Num primeiro modelo que seria puramente procedimental, a constituição contém apenas normas de organização e procedimentos e em relação a legislação e nenhum conteúdo é previamente excluído do direito positivo, assim os limites do direito positivo são restritos a racionalidade ou irracionalidade do legislador, não possuindo os direitos fundamentais força vinculante alguma. Já num segundo modelo, puramente material, seu oposto, a constituição possui normas puramente materiais e tudo se deriva dela, cabendo ao legislador apenas declarar o que lá está estabelecido.

Ambos os modelos seriam os extremos das normas e inviáveis, haja vista que do modelo puramente procedimental exara-se uma decisão ao passo que do modelo puramente material tem-se uma cognição. A Constituição Alemã e a Brasileira possuem natureza mista, possuindo normas de Direito Material (Direitos Fundamentais e Objetivos do Estado) e normas procedimentais (processo legislativo), o que implica na existência de conteúdos possíveis, necessários e impossíveis em relação a Constituição.

O fato das normas de direitos fundamentais serem normas materiais estabelece conteúdos necessários e impossíveis no sistema jurídico ao mesmo tempo que passando a constar na Constituição as transformam num núcleo de fundamentalidade formal desses direitos. A existência de normas numa constituição tidas como imutáveis por emenda constitucional determina ainda que além dos conteúdos necessários e impossíveis vigentes na constituição, há conteúdos necessários e impossíveis em relação à vigência da constituição.

As características formais e materiais das normas de direito fundamental é que permitem que dela se derivem os efeitos formadores das demais normas, dado que sua origem se dá na base dos valores mais caros entendidos àquela sociedade. É a partir da fundamentalidade formal e material que os direitos fundamentais e as normas de direito fundamental desempenham um papel central no sistema jurídico. 


\section{A EFICÁCIA HORIZONTAL DAS NORMAS DE DIREITO FUNDAMENTAL}

Os direitos fundamentais não são apenas direitos do indivíduo perante o Estado, mas representam uma ordem de valores que vale como decisão constitucional fundamental em todos os ramos do direito e que fornece diretrizes e impulsos para a legislação, a administração e a jurisprudência. Mas estes valores percorrem um caminho para tornar-se princípios a partir da sua constitucionalização sendo necessária a análise do próprio sistema jurídico para evidenciar este princípio e sua eficácia.

A análise do sistema jurídico em seus efeitos pode ser feita sob duas perspectivas, a do sistema de normas e a do sistema de posições e relações jurídicas, sendo que ambas as perspectivas oferecem vantagens, já que a análise pelo sistema de normas permite uma abstração e simplificação ao passo que o sistema de posições permite o poder de diferenciação.

A eficácia das normas de direito fundamental se dá pela oponibilidade de direitos precipuamente na relação jurídica estado-cidadão pois o cidadão tem direitos subjetivos ante ao Estado, mas a esta primeira influência, pode-se somar uma segunda, que abarcaria a relação cidadão-cidadão afetando os direitos civis no chamado efeito horizontal, sendo importante esclarecer a forma de irradiação destes princípios.

Pela tese da irradiação os Direitos Fundamentais, por representarem uma ordem objetiva devalores (Princípios) influenciariam todo o sistema jurídico, sem, contudo, serem preponderantes. Encontrar este princípio preponderante passa por três abstrações, uma primeira na qual se retira o elemento subjetivo (titular do direito), uma segunda na qual se retira o obrigado e uma terceira na qual se obtém um deverser, de natureza fundamental axiológica ou mestre, chamado de princípio de nível máximo de abstração, com influência irradiante. Um exemplo simples citado por Alexy (2008) esclarece: abstenção de intervir na manifestação do pensamento - princípio específico e Liberdade de opinião - princípio mestre.

A grande vantagem advinda da existência de princípios supremos é a flexibilidade advinda da ampla aplicação destes como fundamento da decisão, especialmente por serem reflexo necessariamente da escolha democrática legislativa, em que pese a desvantagem da indeterminação já que a decisão de algo concreto partiria de um princípio abstrato. Mesmo assim há base para a aceitação de uma ordem de princípios supremos objetivos com efeitos irradiantes, restando esclarecer como ocorre esse efeito e qual o seu conteúdo.

Desta forma, a apesar de possíveis, as construções dos efeitos são relacionadas a valores, redundando em princípios ampla eficácia, irradiante, ou de eficácia restrita às relações entre particulares e estado, vez que encontram no direito civil um oponente elegível e a altura, qual seja a autonomia privada, cerne do direito comum e trabalhada desde os romanos, portanto pilar do direito ocidental.

O limite é efetivamente tênue entre a abstração valorativa de um princípio cunhado para a proteção ante ao estado e base do direito fundamental e sua aplicação no campo das relações particulares, especialmente se tratando no campo do desenvolvimento econômico e tecnológico, bem como no sistema capitalista cujo modo de produção se baseia nas relações comerciais, na empresa e nos diversos valores advindos do direito civil, no sentido de prover os bens necessários a sobrevivência.

Adiante serão verificadas algumas das teorias mundialmente aplicadas nos países democráticos e ocidentais e mais estudadas no Brasil, de forma a elucidar ainda mais as possibilidades de efeitos dos direitos fundamentais.

\section{AS TEORIAS SOBRE A EFICÁCIA HORIZONTAL DOS DIREITOS FUNDAMENTAIS}

Em que pese a consagrada construção de Alexy, ora usada para a explicitação dos efeitos horizontais dos direitos fundamentais por abarcar o amplo entendimento sobre seus efeitos de forma profunda e 
racional, verifica-se que existe um alcance de atuação dos direitos fundamentais, que vão desde a negação de efeitos perante terceiros que não o Estado até a sua eficácia direta nas relações entre particulares.

De um modo geral, mesmo aqueles que não aceitam a eficácia horizontal, verificam a sua possibilidade e a consideram. Assim a ideia de efeito horizontal é amplamente aceita, o que se discute é como e com qual extensão ela se dá, ou seja, como as Normas de Direitos Fundamentais produzem efeitos entre particular (problema de construção) e qual a extensão destes efeitos (problema de colisão).

Ambas as questões resultam do fato de existir na relação cidadão/cidadão dois titulares de Direitos Fundamentais, sendo que diversas teorias foram propostas neste sentido, sendo as mais aceitas a Teoria dos Efeitos indiretos perante terceiros; a Teoria dos Efeitos diretos perante terceiros; a Teoria de efeitos mediados por direitos em face do Estado, a Teoria da Convergência Estatista e ainda as teorias que embasam a não aceitação dos efeitos ou a sua incidência mínima e específica, como a Teoria da "State Action" e a da "Public Action".

Inicia-se a abordagem pelas teorias que negam o efeito horizontal dos direitos fundamentais, se verifica no seu cerne que decorrem da preservação da autonomia privada, posto serem, na verdade, baluartes desta em detrimento de um intervencionismo estatista.

Conforme se verificará, os caminhos para estas teorias apontaram direções antagônicas: enquanto no direito continental europeu se verificou a concepção de acolhimento dos efeitos horizontais dos direitos fundamentais, no direito Inglês e na América Anglo-Saxônica se verificou sua negação.

Especificamente no caso dos Estados Unidos da América e como de resto, em geral, a aplicação no common law, aplica-se a Teoria do "State Action" que não se admite a eficácia dos direitos fundamentais entre particulares detentores de direitos fundamentais. Preconiza o "State Action" que a autonomia privada tem um caráter axiológico supremo e, portanto, seu transporte para o mundo deontológico adquire status que impede a aplicação de outros valores ainda que supremos em contrário. Tal concepção advém da tradição liberal e clássica dos Norte Americanos, sendo que as bases ideológicas firmadas nas guerras de independência, criaram a concepção de que os direitos individuais são oponíveis apenas ao Estado e, desta forma, inaplicáveis no âmbito das relações privadas (SARMENTO, 2006).

Nos Estados Unidos os direitos às liberdades são fortes e direcionados a abstenção do Poder Público na esfera do particular e permitir que a Constituição atue nas relações interpessoais seria atingir diretamente a liberdade e a base do direito privado, de forma que a doutrina do "State action" entende que a aplicação das dez emendas à Constituição Americana seria direcionada apenas contra ações do Estado, consolidando o direito à liberdade individual ampla, objetivando assegurar as atividades privadas pelo livre exercício da autonomia dos contratantes (autonomia da vontade).

Vale destacar que um case julgado na Suprema Corte em 1946 criou um precedente importante na eficácia horizontal. Trata-se do caso Marshal v. Alabama, no qual uma empresa privada detentora de um terreno urbanizado no qual seus funcionários residiam, com arruamentos e comércio público havia proibido a um religioso que pregasse sua fé naquele ambiente. A Suprema Corte Americana considerou a vedação inválida ao argumento que a empresa mantinha na verdade uma cidade privada e neste sentido a equiparou ao Estado, sujeitando-se a liberdade de culto, direito fundamental garantido pela primeira Emenda à Constituição Norte Americana.

A atenuante formulada na teoria da "public function" assevera que as atividades que são de natureza essencialmente estatal, a despeito de delegação, quando exercidas por particulares devem submeter-se integralmente aos direitos fundamentais previstos na Constituição. A discussão entre alcance constitucional e direitos fundamentais é estritamente vasta, sendo o extremo americano contrastado por toda construção alemã e europeia continental.

A restrição dos efeitos também foi defendida na Alemanha, dentre outros, por Ernest Forstoff, uma vez que os direitos fundamentais aplicados nas relações horizontais, ou seja, diretamente entre detentores de direitos fundamentais, ofenderia a segurança jurídica e acarretaria o comprometimento da liberdade de decisão e da autonomia dos indivíduos (UBILLOS, 2008). 
Para esta corrente os direitos fundamentais, apesar de imprescindíveis nas relações envolvendo o poder público, não poderiam ser aplicados nos casos entre particulares sob pena de corroer o sistema de direito civil, cuja base éa autonomia privada. Esta teoria não teve acolhida no direito alemão, especialmente após a década de 1950 com a decisão do Tribunal Constitucional Alemão admitindo a teoria da eficácia indireta, adiante explicitada.

De outro lado, entre as teorias que aceitam a incidência dos direitos fundamentais nas relações particulares, advém um componente histórico tradicional, a começar dos exemplares estudos alemães, país que emergiu do Nazismo, que por sua vez foi embasado na vigência da pioneira Constituição de Weimar. A doutrina alemã, amplamente difundida e seguida pelos demais países, especialmente o Brasil, oferece um range interessante de teorias sobre os efeitos dos direitos fundamentais, que são aceitos em países com construções históricas e desenvolvimento distinto.

Assim, a Teoria que prevalece no Tribunal Constitucional Alemão é a elaborado por Gunther During, caracterizada por efeitos indiretos perante terceiros, sendo que os julgados devem necessariamente considerar, pelo efeito irradiador, os direitos fundamentais na interpretação do direito privado. Desta forma os efeitos seriam mediatos, ou seja, seriam balizas para a interpretação da legislação ordinária e sua elaboração, expressando valores Constitucionais. Os Direitos fundamentais funcionariam como portas de conexão na interpretação dos preceitos de direito civil ou parâmetros obrigatórios aos Juízes na leitura dos direitos civis (PEREIRA, 2003).

Os direitos fundamentais seriam escolhas axiológicas da sociedade mediadas em sua aplicação no âmbito privado, de forma que a teoria de eficácia mediada é antes de tudo voltada ao legislador infraconstitucional, que deve compatibilizar a legislação aos direitos fundamentais, cabendo ao Judiciário preencherascláusulasindeterminadascriadas pelolegislador, assim comorejeitarporinconstitucionalidade a aplicação de normas privadas incompatíveis com os direitos fundamentais (SARMENTO, 2006).

Assim, somente excepcionalmente pode ser preenchido o espaço eventualmente aberto no ordenamento com os valores constitucionais, pela aplicação direta dos direitos fundamentais nas relações privadas, independente da mediação do legislador. Assegura esta corrente um poder restritivo aos direitos fundamentais em relação a legislação infraconstitucional dado que seria demasiado poder ao Juiz o uso direito de valores tendo em vista o seu grau de indeterminação desses direitos fundamentais. Em última instância a autonomia privada e a própria liberdade individual ficaria à mercê deste poder judicante. Novamente a ofensa a autonomia privada pelos direitos fundamentais é a razão para o freio de sua aplicação plena.

A teoria de efeitos indiretos de During e do Tribunal Federal da Alemanha prevalece naquele país, a despeito de críticas sobre uma eventual insegurança na aplicação de normas legisladas, de um lado, e do outro, sob a ausência de tutela plena dos direitos fundamentais.

A partir destas críticas, ou melhor, visando a tutela plena dos Direitos Fundamentais, Hans Carl Nipperdey elaborou a Teoria dos Efeitos diretos perante terceiros, seguida inclusive pela $\mathfrak{1}^{\mathfrak{a}}$ Turma do Tribunal Federal do Trabalho da Alemanha, que assevera que os Direitos Fundamentais são Direitos Públicos subjetivos e dirigem-se apenas contra o Estado, mas que a influência destas normas de direitos fundamentais no Direito Privado decorre justamente de serem normas de Direito Constitucional vigente, devendo ter efeito absoluto ou efeito normativo direito, especialmente se tratando de tutela de bens personalíssimos.

Apesar não ter aceitação na Alemanha, seu país de origem, a teoria de Nipperdey é majoritária na Espanha, Itália, Argentina e em Portugal, e assevera que categorias de direitos fundamentais previstos na Constituição vinculam apenas os Estados, mas há direitos que podem ser invocados diretamente nas relações privadas, independentemente de qualquer mediação por parte do legislador, revestindo-se de oponibilidade "erga omnes" (UBILLOS, 2008).

A Constituição não seria "neutra", mas veicularia uma ordem objetiva de valores e a despeito de cláusulas gerais ou mesmo de qualquer ponto de inflexão, o seu efeito seria direto, modificando e regenerando as normas jurídicas existentes, conforme destaca Daniel Sarmento (2006, p. 154): "um direito 
fundamental cujo reconhecimento depende do legislador, não é um direito fundamental. (...). O direito fundamental se define justamente pela indisponibilidade de seu conteúdo ao legislador".

Logo, verifica-se o antagonismo entre Nipperdey e During, haja vista que para o primeiro a mediação implicaria em negativa a força normativa dos direitos fundamentais, ante a exigência de atuação legislativa, sendo degradado o direito fundamental e a própria ordem jurídica enquanto considerados os Direitos Fundamentais como normas axiológicas. A tese da eficácia direta demonstra os riscos aos quais os direitos fundamentais estão sujeitos num mundo globalizado no qual não apenas do Estado, mas também terceiros tão ou mais poderosos podem ofendê-los.

Reconhece-se, por outro lado, que esta mesma teoria possua características que a tornam casuísticas, já que a mais uma vez há que se ponderar entre a autonomia privada e o efeito dos direitos fundamentais, especialmente se considerados oponíveis erga omnis, ainda que em alguns deles, uma vez que não são tão homogêneos, havendo a necessidade ponderação dos mesmos no caso concreto.

A Teoria de Jurgen Schwab, denominada Teoria da Convergência Estatista, pela qual os efeitos das normas de direitos fundamentais seriam consequência da vinculação do Estado aos Direitos Fundamentais. Desta forma, o Estado como produtor/julgador do Direito Privado Subjetivo é quem o estabelece e o aplica, e neste sentido acaba por participar de suas violações, mesmo que cometidas por particulares. Assim o Estado é responsável por qualquer agressão a direitos fundamentais, mesmo que no âmbito das relações privadas (SARLET, 2000).

A teoria defende ainda que o próprio direito de autonomia privada decorre do permissivo estatal, e assim, se o Estado permite o descumprimento do direito fundamental, está permitindo e deve por isso ser responsabilizado, atribuindo a violação de um direito ao poder público. A teoria possui aceitação mínima e mereceu a crítica de que se passaria a tutela pública em geral perdendo o sentido em se diferenciar o público e o privado. Ademais, parte de um pressuposto no mínimo questionável de que a liberdade e os direitos fundamentais são uma criação do Estado, merecendo a crítica de totalitária proposta por Daniel Sarmento (2006).

Por fim resta examinar a Teoria de Robert Alexy, que consiste num modelo de três níveis que explica os efeitos das normas de direitos fundamentais. O modelo faz uma crítica sistemática as três teorias sobre os efeitos ao mesmo tempo que as compatibiliza de forma racional, de acordo com jurisprudência do Tribunal Federal da Alemanha.

Para Alexy as três teorias que visam explicar os efeitos horizontais dos direitos fundamentais se equivalem em resultado, ou seja, o mesmo resultado pode ser obtido por qualquer uma delas. Isso ocorre porque todas entendem que a relação dos Direitos Fundamentais é uma relação horizontal, na qual todos possuem Direitos Fundamentais e que todos os direitos necessitam de modulação dos efeitos. Mais pois para todas as teorias sobreditas a medida do efeito é um sopesamento, que pode afastar um DF em relação a outro. Logo, se se analisar as coisas pelo resultado, o decisivo não é a construção, mas a valoração que preenche (ALEXY, 2008).

Considerando estas premissas, Alexy propôs um modelo em três níveis para os efeitos perante terceiros, pois apesar das três teorias apresentarem resultados equivalentes e aceitáveis, há que procurar uma construção correta, um modelo que abranja todas as características das complexas relações jurídicas dos efeitos perante terceiros, já que cada uma das três teorias destaca alguns destes efeitos.

O modelo proposto por Alexy compõem-se por três níveis, sem relação de grau e com mútua implicação, um primeiro nível estatal com as Normas de Direito Fundamental como princípios numa ordem objetiva de valores, implica que o Estado tem o dever de leva-las em conta tanto na legislação quanto na jurisprudência; um segundo nível de direitos em face do Estado no qual há necessidade conexão entre as Normas de Direito Fundamental e a aplicação/interpretação da norma de direito civil para que a jurisprudência da corte suprema seja consistente ao mesmo tempo que não viole os Direitos Fundamentais.

Por fim há um terceiro nível que seria a relação jurídica em face do Estado e que diz respeito aos efeitos dos Direitos Fundamentais nas relações jurídicas de Direito Privado, que seria o efeito sobre 
terceiros propriamente dito. Como não há Direito Fundamental de um cidadão em face de outro cidadão e tampouco há como requerer efeitos de Direitos Fundamentais de um cidadão em face de outro como substituto do Estado, os efeitos diretos decorrem dos efeitos indiretos aliados aos efeitos mediados pelo Estado.

Haveria uma complementariedade entre os três níveis pelas três teorias, com o primeiro nível na teoria do efeito mediato e os juízes teriam o dever de Estado de levar em consideração os direitos fundamentais, como valores objetivos, na interpretação e aplicação das normas de direito privado. No segundo nível os deveres de proteção colocariam o Judiciário com a obrigação de considerar os direitos fundamentais sob pena de violá-los. No terceiro nível pertinente às relações entre particulares incidiria a teoria da eficácia imediata, podendo a Constituição e os direitos fundamentais serem oponíveis erga omnes aos particulares (ALEXY, 2008).

A grande vantagem do modelo de Alexy reside na questão da fundamentação da decisão, que pela adoção dos três modelos possibilita um nível de atendimento maior desta ao passar pelos três níveis adotados, não havendo primazia entre os níveis, pois cada um aborda um aspecto, e o processo ser conduzido de forma racional.

As críticas ao modelo de três níveis passam exatamente pelas críticas orientadas as teorias de suporte e que se concentram na restrição a autonomia privada, crítica refutável pelo fato de a própria autonomia privada ser objeto de garantia constitucional e dela advir efeitos perante terceiros. Noutra crítica, calcada numa eventual restrição do papel do Direito Civil e no uso direito das Normas de Direito Fundamental pode ser elidida uma vez que os princípios de Direitos Fundamentais não determinam uma única solução aos casos, fato que confere a importância ao Direito Civil a tomada de decisões, como seu subsídio, sendo que as decisões dos casos devem ser apoiadas na Lei Civil, Precedentes e proposições dogmáticas aceitáveis. Desta forma o Juiz civil está vinculado ao direito civil vigente e ao afastar-se disso assume os ônus argumentativos ao usar os Direitos Fundamentais (ALEXY, 2008).

\section{O DESENVOLVIMENTO E A EFICÁCIA HORIZONTAL DOS DIREITOS FUNDAMENTAIS}

Consideradas as principais teorias sobre os efeitos dos direitos fundamentais, cumpre destacar que o estabelecimento de conteúdos constitucionais como direitos fundamentais não necessariamente determina sua efetividade. Com efeito, a maioria dos países ocidentais tem os valores de liberdade e igualdade arraigados em suas Constituições, mas muitos deles não possuem níveis de desenvolvimento social e econômico que viabilizem a efetividade destes direitos, o que na prática significa que não podem provê-los, e sequer conseguem manter-se democraticamente estabelecidos, como Venezuela, Equador e Bolívia, ante a comunidade internacional ${ }^{3}$, em avaliação do site especializado The Economist (2017).

Dentro da discussão desta efetividade, a adoção de uma ou outra teoria acaba por ter um efeito político, haja vista que, em princípio, indicaria a tutela maior ou menor de um Estado em defesa aos direitos fundamentais, ou o quão a sua corte suprema considera a sua capacidade de valer-se diretamente das normas constitucionais de direitos fundamentais nas relações puramente privadas. Este efeito aparentemente positivo das normas pode ter também um efeito negativo, que é a produção de uma norma que transfere para o plano jurídico discussões cabíveis no plano legislativo e democrático, além de produzir uma falsa sensação de proteção normativa.

Importante destacar neste sentido o fechamento do sistema jurídico, como destaca Marcelo Neves (2007):

$3 \mathrm{O}$ índice de democracia é medido e publicado anualmente pela revista The Economist e o The Economist Intelligence Unit (EIU) considera cinco categorias gerais: o processo eleitoral e pluralismo, as liberdades civis, o funcionamento do governo, participação política e cultura política. 
Sendo assim, o sistema jurídico pode assimilar, de acordo com os seus próprios critérios, os fatores do ambiente, não sendo diretamente influenciado por esses fatores. A vigência jurídica das expectativas normativas não é determinada imediatamente por interesses econômicos, critérios políticos, representações éticas, nem mesmo por proposições científicas, pois depende de processos seletivos de filtragem conceitual no interior do sistema jurídico (NEVES, 2007).

Desta forma, a aplicação das normas fundamentais como conteúdo de Direito Constitucional em confronto com o ordenamento civil requer mais do Judiciário, eminentemente técnico. A consideração da contextualização histórica e valorativa da sociedade e especialmente o grau de desenvolvimento são fatores importantes a se considerar na eventual aplicação dos efeitos horizontais dos direitos fundamentais e na sua efetividade.

Paralelamente há uma discussão mundial sobre o direito e o desenvolvimento, especialmente considerada sobre as políticas públicas e a promoção do desenvolvimento com normas ou mesmo com reformas judiciais. Para muitos é uma forma de resguardar o direito ao desenvolvimento, fazendo-o constar como direito humano e fundamental, ou "As necessidades fundamentais não devem ficar condicionadas à caridade de programas e políticas estatais, mas sim definidas como direitos” (EIDE E ROSAS, 1995).

A capacidade do chamado império do direito de promover o desenvolvimento é questionável, porém cabe ao Sistema Jurídico, no mínimo, prover um ambiente seguro para que as relações jurídicas operem de forma previamente conhecida, de um lado preservando os direitos fundamentais e de outro tutelando a autonomia privada. A efetividade da justiça implica em desenvolvimento, ou , em outras palavras "parece haver, portanto, alguma correlação entre desenvolvimento e um sistema jurídico sólido" (GICO JUNIOR, 2017).

Ademais, se os direitos civis e políticos mantêm a democracia dentro de limites razoáveis, os direitos econômicos e sociais estabelecem os limites adequados aos mercados. Mercados e eleições, por si só, não são suficientes para assegurar direitos humanos para todos, conforme Donnelly (1998). Assevera ainda Trubek (1984, p. 207), que "Os direitos sociais, enquanto social welfare rights, implicam na visão de que o governo tem a obrigação de garantir adequadamente tais condições para todos os indivíduos".

O desenvolvimento econômico há muito não é um indicativo de desenvolvimento dos cidadãos e o outrora incontestável Produto Interno Bruto passou a ferramenta dos economistas, passando a ONU a eleger o Índice de Desenvolvimento Humano (IDH) como baliza atual para as discussões sobre desenvolvimento. especialmente se considerar que é o índice oficial das Nações Unidas.

O IDH é uma ferramenta econômica desenvolvida pelos economistas Mahbub ul Haq e Amartya Sem, nos anos 1990, exatamente para contrapor ao PIB índices sociais e humanizar a medida do PIB, e de maneira simples fornecer um dado comparativo a nível mundial. Vem sendo usado anualmente desde 1993 para medir, comparar e classificar o "desenvolvimento humano", considerando PIB per capta aliado a expectativa de vida e a educação formando um índice de padrão de vida.

Consoante a proposta pós era imperialista, ao fim da Segunda Guerra Mundial, a busca pelo desenvolvimento sócio econômico é um ideal que traz a reboque a melhoria do país e da condição de seus cidadãos. Neste sentido, a discussão em torno do Direito enquanto ferramenta que pode trazer melhoria nos níveis sociais ganha grande destaque e permite conclusões, em direito comparado, sobre a tentativa de conciliar justiça social e segurança jurídica, Gico Junior (2017). E neste ponto a intervenção do Estado-Juiz nas relações privadas com normas de direitos fundamentais é extremamente importante.

Com efeito, num mundo capitalista a interferência na autonomia privada é vista como dúbia, e a discussão sobre os efeitos horizontais dos direitos fundamentais é tratada de forma delicada, já que por um lado há que se preservar a independência das relações econômicas visando a produção, a iniciativa, a empresa e a tecnologia como geradores de riqueza e empregos ao mesmo tempo que há que se tutelar a sociedade, o ser humano e seus direitos fundamentais.

Desta forma, as diversas sociedades têm se desdobrado na busca e priorização destas duas 
conflitantes realidades, num mundo regrado por normas de direito civil, um ramo do direito desenvolvido há milênios, uma instituição consolidada nos diversos países, mas obviamente não imune as normas constitucionais. As diversas aplicações de teorias de direitos fundamentais nos diversos países buscam exatamente equilibrar estes lados, num mundo globalizado, com novos atores internacionais e os Estados em crise (MORAIS, 2011).

A limitação dos efeitos horizontais dos direitos fundamentais nos Estados Unidos, bem como a adoção pelos Alemães da Teoria de Efeitos Mediatos tem razões centradas também no desenvolvimento atingido por aqueles países.

Os Estados Unidos possuem um IDH altíssimo de o,915 (PNUD, 2015), estando em 8o lugar na escala global para a $3^{\mathrm{a}}$ maior população mundial e com um PIB de 18,04 trilhões de dólares, de acordo com o The World Factbook da CIA (2017) e foram historicamente edificados numa base de respeito a autonomia privada que faz da liberdade e da iniciativa dos seus cidadãos uma força produtiva e que determina o reconhecimento dos direitos fundamentais esmagadoramente voltados contra atos cerceadores estatais. A despeito das eventuais desigualdades, a liberdade de ação é venerada e a "aposta" social é na capacidade individual, mesmo que considerada exageradamente individualista (SARMENTO, 2006).

Importante ainda frisar que o Direito Civil Americano é de competência dos Estados e não da Federação, fato que por si só comprometeria o espaço desta autonomia dos entes federados.

A Alemanha possui o $4^{0}$ maior IDH do planeta com o,916 pelo PNUD (2015) e diferentemente dos americanos aceita amplamente os efeitos horizontais, mas não os aplica diretamente posto se tratarem de um conjunto de valores transmudados do mundo axiológico para o mundo deontológico, necessitando de "modulação" em sua aplicação e efeitos, pelo que adota a teoria da eficácia mediada de During. Com um PIB de 4,14 trilhões de dólares (CIA, 2017), assim como os EUA, tem uma economia extremamente estável.

A adoção de princípios na Alemanha, neste caso, é claramente uma proteção extra ao sistema judicial de um eventual confronto com a autonomia privada. Desta forma, a associação de alto nível social num país altamente industrializado (e que prima pela alta tecnologia), considera a aplicação dos direitos fundamentais nas relações privadas aliando-a às preocupações com um eventual cerceamento a autonomia privada no campo econômico, eventualmente provocado por interpretações diretas de normas de direitos fundamentais, com adoção de um modelo de efeitos mediados.

Portugal, Espanha e Itália, com índices de desenvolvimento humano respectivos de o,830; o,876 e o,873 (PNUD, 2015), e, portanto, elevados, não possuem economias poderosas e sólidas como Alemanha e Estados Unidos, especialmente a considerar pelo PIB de cada um, se comprados àqueles, com Espanha com PIB de 1,769 trilhões de dólares; Itália 2,307 trilhões de dólares e Portugal o,311 trilhões de dólares (CIA, 2017). Não obstante, ao menos teoricamente oferecem tutela ampla e direta aos direitos fundamentais, conforme assevera Sarmento (2006), com a aplicação direta dos efeitos destas normas em seus ordenamentos, valendo-se dos moldes da Teoria dos Efeitos Diretos. Neste sentido, entre a tutela a autonomia privada e a liberdade, penderia em favor de um fortalecimento da igualdade com a atuação do Estado Juiz no sentido de prover o valor constitucionalmente estabelecido, em detrimento de uma eventual iniciativa privada.

A Argentina, ainda segundo Sarmento (2006), adota a teoria dos efeitos diretos. Trata-se de um país em desenvolvimento, mas com um IDH de o,836 (PNUD, 2015), considerado elevado. Sua economia é também menos sólida se comparada a boa parte dos grandes países em desenvolvimento, dado que seu PIB é o,911 trilhões de dólares (CIA, 2017). Mais uma vez a componente histórica e social foi determinante, com a ligação fraterna aos estudos ibéricos e a visão continental latina de Estado provedor, a despeito dos recursos mais limitados.

O Brasil também possui a jurisprudência do Supremo Tribunal Federal alinhada com a proteção efetiva dos valores Constitucionais, de forma que a Teoria dos Efeitos Diretos prevalece nos seus julgados. O Brasil possui o IDH mais baixo em relação a boa parte dos países industrializados com economia forte (mas instável), 79ª posição no IDH com o,755 (PNUD, 2015), e pauta-se pela aplicação direta dos efeitos 
das normas de direitos fundamentais tal qual seus pares latinos. Seu PIB consideravelmente elevado 3,219 trilhões de dólares (CIA, 2017), indica uma economia consideravelmente sólida.

Como se verifica, nesta pequena explanação superficial, a relação entre o IDH e a aplicação dos efeitos horizontais de forma direta ou mediada acontece também de acordo com o desenvolvimento econômico: países com tradição capitalista, de empreendedorismo e com alto poder financeiro tendem a cercear menos a autonomia privada (buscando suas vantagens como a competição e a criatividade) em valoração ante as normas de direitos fundamentais nos seus efeitos horizontais, mediando, restringindo e não admitindo os seus efeitos.

Por outro lado, países com desenvolvimento médio-elevado e em desenvolvimento tendem a aumentar a valoração das normas de direitos fundamentais em seus efeitos horizontais na expectativa de proteger seus cidadãos de eventuais violações na área privada. Estes fatos ajudam a explicar, em geral, a acolhida das teses de eficácia horizontal dos direitos fundamentais pelos Estados, numa análise quantitativa de seu IDH, mas, também, qualitativa ou de mérito dos autores.

\section{CONSIDERAÇÕES FINAIS}

As implicações de sistemas jurídicos fortes e confiáveis ultrapassam o campo social e desembocam no campo econômico, posto ser a economia interessada nas decisões e na segurança sobre os negócios a serem realizados nos países, bem como advir da economia os recursos para a sociedade. Desta forma, a aplicação dos efeitos horizontais dos direitos fundamentais em cada país implica no reconhecimento de suas condições cumprir os contratos e no sentimento de ambiente negocial, na abertura de empregos e na própria industrialização deste país.

Ao confrontar com o IDH de cada um deles, verifica-se que a despeito de priorizar normas fundamentais em seus efeitos horizontais ou a autonomia privada, pode-se pontuar que o estabelecimento de um sistema judicial sólido, estável e confiável a partir de premissas constitucionais que consideram os valores da sociedade, tem-se a base para a formação de uma sociedade mais humanamente desenvolvida.

Obviamente que a discussão proposta é profunda, mas ao menos superficialmente verifica-se uma diferença de estágio de solidez econômica e de IDH antea tutela específica dos efeitos dos direitos fundamentais nas relações entre particulares, sendo inversamente proporcional a concessão de tutela de constitucional ante a autonomia privada nos países mais “desenvolvidos" em relação aos menos "desenvolvidos".

A tutela dos direitos fundamentais em seu efeitovertical éprontamente pacificada e indiscutível nos países desenvolvidos, ao passo que muita mais programática e futurística nos países menos desenvolvidos, já a tutela dos direitos fundamentais em seus efeitos privados é prontamente defendida nos países menos desenvolvidos apontados na pesquisa ao passo que discutida e aplicada com restrição (alta ou baixa) nos países plenamente desenvolvidos.

Se por um lado a defesa é louvável ante a efetiva necessidade de aplicação ampla dos direitos fundamentais, por outo lado é de se lamentar o cerceamento do autonomia privada no sentido do desenvolvimento econômico e social, base do desenvolvimento geral dos Estados exatamente nos Estados que mais precisam e, principalmente, a pseudodefesa dos direitos fundamentais exatamente quando o detentor da obrigação de respeito não é o Estado, ou seja, o Estado não o provê mas quando se trata de censurar o particular, a aplicação é imediata.

A discussão sobre desenvolvimento, especialmente em Estados como o Brasil é extremamente ideológica e a busca por justiça social, combate à desigualdade e outras "bandeiras" levantadas por partidos e ativistas normalmente conduz a políticas públicas populistas, que só fazem aumentar as referidas necessidades, repetindo os ciclos históricos ao invés de aprender com eles.

A aplicação das normas de direito, mesmo as normas de direitos fundamentais, é feita num mundo real e não num ideário de sonhos, uma realidade assimilada pelos países desenvolvidos, sempre cientes 
de que o jogo é feito num mundo capitalista. É preciso repensar o papel do Estado e aplicação das normas para o Estado antes de aplicar normas pelo Estado, pois tutelar direitos fundamentais e promover a disputa privada imputando obrigações aos cidadãos enquanto o Estado não as cumpre é mais uma vez passar o ônus Estatal aos seus cidadãos, já assoberbados de obrigações. O cerne dos Direitos Fundamentais é justamente a tutela dos abusos públicos em relação aos privados e seus direitos fundamentais coletivos e individuais.

\section{REFERÊNCIAS}

ALEXY, Robert. Teoria dos Direitos Fundamentais. Tradução de Virgílio Afonso da Silva. São Paulo: Malheiros, 2008.

CIA. The World Factbook. 2017. Langley, USA. Disponível em: <https://www.cia.gov/library/ publications/the-world-factbook/rankorder/20o1rank.html> Acesso em: 13 abr. 2018.

DONNELLY, Jack. International Human Rights. Colorado: Westview Press, p. 16o, 1998.

EIDE, ASBJORN \& ROSAS, ALLAN. Economic, Social and Cultural Rights: A Universal Challenge. In: A. Eide et al., 1995.

GICO JUNIOR, Ivo Teixeira. Direito \& Desenvolvimento: o papel do direito no desenvolvimento econômico. Direito e Desenvolvimento, v. 8, n. 2, p. 110-127, dez. 2017. ISSN 2236-0859. Disponível em: <https:// periodicos.unipe.br/index.php/direitoedesenvolvimento/article/view/370>. Acesso em: o3 dez. 2017.

MORAIS, José Luiz Bolzan de. As Crises do Estado e da Constituição e a Transformação Espaçotemporal dos direitos humanos. 2. ed. Porto Alegre: Livraria do Advogado, 2011.

MORAIS, José Luiz Bolzan de. A Constituição Concretizada: construindo pontes com o público e o privado. In: SARLET, Ingo Wolfgang (Org.). Porto Alegre: Livraria do Advogado, 2000.

NEVES, Marcelo. A Constitucionalização Simbólica. 2. ed. São Paulo: Martins Fontes, 2007.

PEREIRA, Jane Reis Gonçalves. Apontamentos sobrea Aplicação das Normas de Direito Fundamental nas Relações Jurídicas entre Particulares. Texto extraído do livro A nova Interpretação Constitucional. Organizador: Luís Roberto Barroso. Rio de Janeiro: Renovar, 2003.

PNUD 2015. Human Development Statistical Tables. Human Development Report. New York: United Nations Development Programme. 2015. Disponível em: <http://hdr.undp.org/sites/default/files/2015 human_development_report.pdf $>$ Acesso em: 10 dez. 2017.

PNUD 2017. Human Development Report 2016. Disponível em: <http://hdr.undp.org/sites/default/ files/HDR2016_EN_Overview_Web.pdf> Acesso em: 10 dez. 2017.

SARLET, Ingo. Direitos Fundamentais e Direito Privado: Algumas Considerações em Torno da Vinculação dos Particulares aos Direitos Fundamentais. In: (Org.). A Constituição Concretizada: Construindo Pontes com o Público e o Privado. Porto Alegre: Livraria do Advogado, p. 16o, 2000. 
SARMENTO, Daniel. Direitos fundamentais e relações privadas. 2. ed. Rio de Janeiro: Lúmen Juris, 2006.

THE ECONOMIST INTELIGENCE UNIT, 2017. Londres, UK, 2017. The Economist Intelligence Unit's Democracy Index. Disponível em: <https://infographics.economist.com/2017/DemocracyIndex/> Acesso em: 10 dez. 2017.

TRUBEK, David. Economic, Social and Cultural Rights in the Third World: Human Rights Law and Human Needs Programs. In: T. Meron (ed.). Human Rights in International Law: Legal and Policy Issues. Oxford, Claredon Press, p. 207, 1984.

UBILLOS, Juan Maria. Eficacia horizontal de los derechos fundamentales: las teorias y la practica. In: TEPEDINO, Gustavo (org.) Direito civil contemporâneo: Novos problemas à luz da legalidade constitucional, São Paulo: Atlas, p. 219-237, 2008. 